\title{
Role of family support and women's knowledge on pregnancy-related risks in adherence to maternal iron-folic acid supplementation in Indonesia
}

\author{
Luh Ade Ari Wiradnyani ${ }^{1,2, *}$, Helda Khusun ${ }^{1}$, Endang L Achadi ${ }^{3}$, Dwiana Ocviyanti ${ }^{4}$ \\ and Anuraj H Shankar ${ }^{5}$ \\ ${ }^{1}$ SEAMEO Regional Center for Food and Nutrition, Universitas Indonesia, SEAMEO RECFON Building, Kampus \\ Universitas Indonesia, Salemba Raya no. 6, Jakarta Pusat 10430, Indonesia: ${ }^{2}$ Department of Nutrition, Faculty of \\ Medicine, Universitas Indonesia, Jakarta, Indonesia: ${ }^{3}$ Department of Nutrition, Faculty of Public Health, Universitas \\ Indonesia, Jakarta, Indonesia: ${ }^{4}$ Department of Obstetrics and Gynecology, Faculty of Medicine, Universitas \\ Indonesia, Jakarta, Indonesia: ${ }^{5}$ Harvard T.H. Chan School of Public Health, Boston, MA, USA
}

Submitted 29 March 2015: Final revision received 23 January 2016: Accepted 31 March 2016: First published online 16 May 2016

\begin{abstract}
Objective: To examine whether women's knowledge of pregnancy-related risks and family support received during pregnancy are associated with adherence to maternal iron-folic acid (IFA) supplementation.

Design: Secondary data analysis of the 2002-03, 2007 and 2012 Indonesia Demographic and Health Survey. Analysis of the association between factors associated with adherence (consuming $\geq 90$ IFA tablets), including the women's knowledge and family support, was performed using multivariate logistic regression.

Setting: National household survey.

Subjects: Women ( $n$ 19133) who had given birth within 2 years prior to the interview date.

Results: Knowledge of pregnancy-related risks was associated with increased adherence to IFA supplementation (adjusted OR $=1 \cdot 8 ; 95 \%$ CI 1.6, 2.0), as was full family (particularly husband's) support (adjusted OR=1.9; 95\% CI 1.6, 2.3). Adequate antenatal care (ANC) visits (i.e. four or more) was associated with increased adherence (adjusted $\mathrm{OR}=2 \cdot 2 ; 95 \%$ CI 2.0, 2.4). However, ANC providers missed opportunities to distribute tablets and information, as among women with adequate ANC visits, 15\% reported never having received/bought any IFA tablets and $30 \%$ had no knowledge of pregnancy-related risks. A significant interaction was observed between family support and the women's educational level in predicting adherence. Family support significantly increased the adherence among women with $<9$ years of education.

Conclusions: Improving women's knowledge of pregnancy-related risks and involving family members, particularly the husband and importantly for less-educated women, improved adherence to IFA supplementation. ANC visit opportunities must be optimized to provide women with sufficient numbers of IFA tablets along with health information (especially on pregnancy-related risks) and partner support counselling.
\end{abstract}

Keywords

Family support

Knowledge

Maternal iron-folic acid supplementation
The increased Fe requirement during pregnancy accompanied by insufficient intake of Fe-rich foods puts pregnant women at high risk of Fe deficiency ${ }^{(1)}$, the main cause of anaemia $^{(2)}$. Maternal iron-folic acid (IFA) supplementation is one of the key interventions to reduce anaemia in pregnant women. However, despite consistent findings indicating the efficacy of IFA supplementation, the effectiveness of the large-scale programmes remains low ${ }^{(3)}$.
Women's low adherence to IFA tablet consumption is known as one of the main constraints on programme effectiveness $^{(4)}$. Studies in Vietnam ${ }^{(5)}$, the Philippines ${ }^{(6,7)}$, Senegal $^{(8)}$, Tanzania ${ }^{(9)}$, Bangladesh ${ }^{(10)}$ and India ${ }^{(11)}$ have shown that low utilization of antenatal care (ANC), low supply of IFA tablets, experience of side-effects, perceived benefit of taking the tablets, forgetfulness, counselling from health providers and traditional beliefs are among the 
factors associated with women's adherence. In addition, the influence and relative contribution of these factors to adherence may be setting-specific ${ }^{(9)}$.

Indonesia has implemented maternal IFA supplementation as part of ANC programmes for nearly 40 years $^{(12)}$. Yet, available data from 1991 to 2013 show that the prevalence of anaemia among pregnant women is persistently $\operatorname{high}^{(13,14)}$, at $37-50 \%$, indicating a severe public health problem ${ }^{(15)}$. This may be due, in part, to low effectiveness of the IFA supplementation programme ${ }^{(13)}$. This is consistent with the low adherence of women to IFA tablet consumption reported in a series of three Indonesian Demographic and Health Surveys (IDHS; 2002-03, 2007 and 2012), in which approximately $20 \%$ of women did not consume any IFA tablets during their last pregnancy and only approximately $30 \%$ consumed at least ninety tablets, as recommended ${ }^{(15-17)}$. This heterogeneity in adherence together with heterogeneity in factors previously reported to affect IFA tablet consumption suggests that Indonesia is a suitable proxy for examining the factors associated with adherence to IFA supplementation, with a special focus on the effects of women's knowledge of pregnancy-related risks and family support, as these two areas have received little attention. Understanding the influence of these factors, in combination with others, on adherence to taking the recommended number of IFA tablets would enable a more focused approach to enhance programme impact.

As described above, the present study hypothesizes that women's knowledge of pregnancy-related risks as well as family support during pregnancy are significant predictors of adherence to IFA tablet consumption. The hypothesis was based on the characteristics of the IFA supplementation programme, wherein tablets must be consumed daily for a long period with limited direct assistance and supervision from the ANC provider. As such, high self-motivation and a supportive environment are crucial. Women's knowledge of their pregnancy-related risks represents an internal factor affecting motivation, while family support represents an external factor that creates a supportive environment and, thus, facilitates adherence $^{(18)}$.

\section{Methods}

\section{Data sources}

The current analysis used data from the 2002-03, 2007 and 2012 IDHS. The data sets are in the public domain and can be accessed at the Demographic and Health Survey (DHS) website (www.measuredhs.org). They were the fifth, sixth and seventh DHS, respectively, conducted in Indonesia under the auspices of the DHS programme. The 2002-03 IDHS covered all twenty-six provinces existing at the time of survey, which grew to thirty-three provinces in the 2007 and 2012 IDHS due to the establishment of new provinces from division of older ones.
The IDHS sample was designed to produce representative estimates at the national, urban-rural and provincial levels, with census blocks as the primary sampling unit. In each province, the selection of census blocks in urban and rural areas was performed using multistage stratified sampling. In urban areas, in the first stage, census blocks were selected using systematic random sampling. In each selected census block, twentyfive households were randomly selected. In rural areas, the household selection was performed in three stages. In the first stage, sub-districts were selected with a probability proportional to the number of households. In the second stage, from each selected sub-district, census blocks were selected using systematic sampling. In the third stage, in each cluster, twenty-five households were randomly selected. In total, 33088, 40701 and 43852 households were interviewed in the 2002-03, 2007 and 2012 IDHS, respectively, with a response rate of $99 \%$. From the households, 29483, 32895 and 45607 women and 8310, 8758 and 9306 men were interviewed for the 2002-03, 2007 and 2012 IDHS, respectively ${ }^{(15-17)}$.

\section{Participants}

The current analysis includes women who gave birth within 2 years prior to the date of the interview. When the woman had more than one child aged 0-23 months ( $2.6 \%$ of the sample), information on pregnancy of the younger child was selected. The present analysis included 19133 out of a total of 19646 mothers of children aged 0-23 months from the IDHS 2002-03 to 2012, with subtotals of 5835 (2002-03), 6468 (2007) and 6830 (2012) mothers (the numbers are adjusted by the sampling weights). In addition, data from the husbands of the women ( $n$ 4969) were also used for the additional analysis of family support. In the IDHS rounds, all currently married men aged 15-54 years living in every third household in the IDHS sample were interviewed.

\section{Study variables}

The outcome of the analysis was the adherence of women to the recommendations of the IFA supplementation programme, indicated by consuming minimally ninety IFA tablets during the most recent pregnancy in the last 2 years. The women were asked: 'For how many days during this pregnancy did you take the iron tablets? Women who reported never receiving or buying IFA or Fe-containing tablets during the pregnancy were coded as consuming 0 IFA tablets. Mothers who did not know whether they received or bought IFA or Fe-containing tablets $(1.1 \%)$ or did not know the number of IFA or Fe-containing tablets consumed (5.0\%) during the recalled pregnancy were excluded from the analysis. Women reporting a consumption of $>240$ IFA or Fe-containing tablets during pregnancy (5.3\%) were also not included in the analysis, because the consumption of $>240$ tablets was 
considered implausible and attributed to either mistaken recollection or a data recording error ${ }^{(19)}$.

Findings from previous studies ${ }^{(5,7,10,11,20-22)}$ were referred to in constructing the conceptual framework of the study, as outlined in Fig. 1. The explanatory factors for adherence were socio-economic/demographic factors (household wealth index, type of residence, women's age, pregnancy order, women's educational level), healthservice access and utilization (perceived problems accessing health services, frequency of ANC visits), women's knowledge (women's knowledge on pregnancyrelated risks, women's exposure to information) and family support (women having discussions with anyone on delivery-related issues, women being accompanied by her husband/partner for any ANC visit).

The household wealth index was developed using principal component analysis of the household's ownership of a number of consumer items (such as television, refrigerator, motorcycle), housing materials (wall, roof and floor materials) and household facilities (type of toilet, source of drinking water, cooking fuel). The scores obtained from the principal component analysis were then used to set the points that grouped the household into quintiles, with the first quintile being the poorest and the fifth quintile being the richest ${ }^{(15-17)}$. Perceived problems accessing health services were generated from the mothers' response to the question: 'When you are sick and want to get treatment, is each of the following (getting permission to go/getting money needed for treatment/ distance to the health facility/not wanting to go alone) a big or not a big problem?' The women were categorized as having problems accessing health services if they perceived at least one of the four factors as a problem.

The adequacy of ANC visits was defined by the number of ANC visits made during each trimester of pregnancy. The women were asked: 'How many times did you receive antenatal care in the first 3 months? Between the 4 th and 6th month? Between the 7th month and delivery?' The women were categorized as having an adequate frequency of ANC visits when they had minimally one visit each during the first and second trimester and minimally two visits during the third trimester. Women who reported

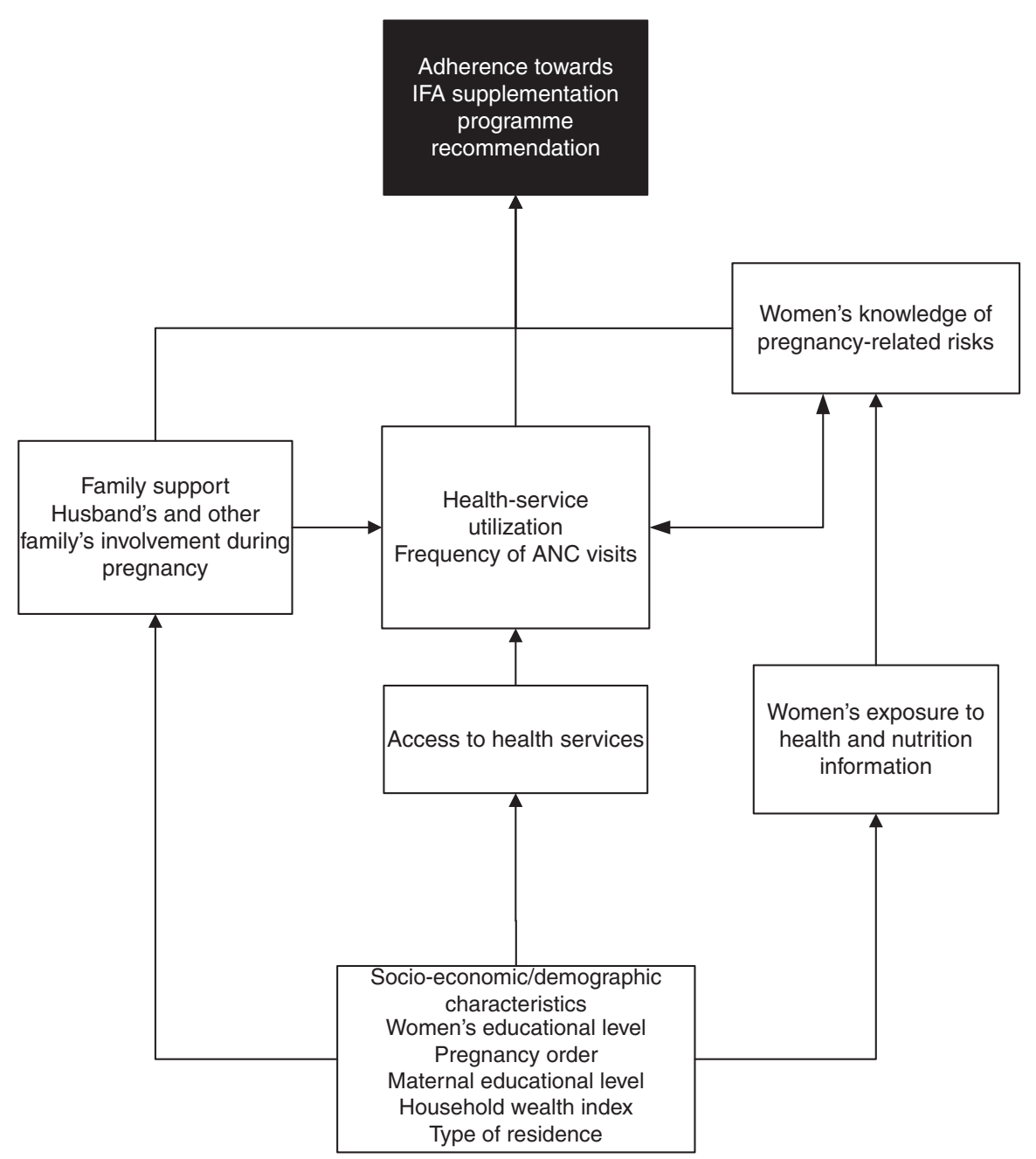

Fig. 1 Conceptual framework of the study (IFA, iron-folic acid; ANC, antenatal care) 
having 'ANC visits' with traditional birth attendants or other than health providers $(5.4 \%)$ were categorized as having an inadequate frequency of ANC visits.

Exposure to mass media (television, radio, magazines/ newspapers) was used as an indicator of the women's exposure to information, which may include health and nutrition information. 'Less exposed' referred to never having exposure to the media or having exposure less than once weekly, while 'frequently exposed' referred to having exposure to the media almost every day or at least once weekly. The women were grouped into three categories based on their knowledge of pregnancy-related risks, i.e. whether they were able to answer questions about the problems/symptoms that women might have during pregnancy, delivery and after birth. They were grouped as 'has no knowledge' when they did not know/could not answer all three questions, 'has some knowledge' when they could correctly answer one or two of the three questions, and as 'has good knowledge' when they could correctly answer all three questions.

Family support was derived from two variables, i.e. whether the women were accompanied by a husband/ partner in any ANC visits during the recalled pregnancy $(0=$ no, $1=y e s)$ and whether, during their pregnancy, the women discussed issues related to their delivery plan with anyone (i.e. place to deliver, transportation to the place of deliver, who is going to assist with the delivery, payment for the delivery and identifying a blood donor). When we performed further analysis using the merged women's and husbands' data sets ( $n$ 3902), it was revealed that among women who reported to have discussions about at least one delivery-plan topic, $81.7 \%$ of their husbands also reported having discussions on such topics. Therefore, we considered that the person with whom the women had the discussion was primarily the husband. Thus, the support was labelled 'family support'. The scores were compiled based on the five delivery-plan issues discussed by the women (i.e. $0=$ never had discussion; $1=$ discussed some issues; $2=$ discussed all issues). The family support scores were then used to categorize the women into three groups, i.e. 'received no support' (women were not accompanied by a husband/partner during their ANC visits and never had discussion on delivery-related issues, and thus were scored 0), 'received full support' (women were accompanied by a husband/partner during ANC visits and discussed all delivery-related issues, and thus were scored 3) and 'received some support' (women who did not belong to the above two categories, and thus were scored 1-2).

\section{Statistical analysis}

Descriptive analysis was conducted to describe the profile of the participants in the analysis. Bivariate logistic regression was employed to estimate the crude odds ratios, with 95\% confidence interval, for the association between the dichotomous outcome variable (mother's adherence to the IFA supplementation programme) and each of the explanatory factors without adjusting for other factors. All of the factors associated with mother's adherence in bivariate analyses (defined as $P \leq 0.25$ ) were included in a multivariate logistic regression to identify those significantly associated with adherence. The possibility of collinearity among associated factors included in the multiple regressions was examined, which was indicated by either changes in the direction of effect or changes in the significance of effect between the bivariate and multivariate analysis for the particular factor.

Variations by residence were almost entirely explained by the wealth index, indicated by the decrease of adjusted odds ratio (from 1.6 to $1 \cdot 1$ ) when the variable "wealth index' was entered into the model, indicating possible collinearity between residence and wealth index. We decided to include the wealth index, instead of residence, in the final regression analysis because residence was included to address the difference between urban and rural regions mainly in terms of health-service access and utilization, as well as the women's exposure to information, which were included as predictors of adherence in the regression analysis. Moreover, the women's educational level became no longer a significant predictor when family support was entered into the model, suggesting that both variables may have large shared variance and thus are correlated. Therefore further analysis was performed to examine the interaction between the women's educational level and family support.

Due to missing values, the number of participants in the multivariate logistic regression analysis was 15958 (3175 or $16.6 \%$ of participants had missing values for one or more variables). Regression analysis was adjusted by the current age of the child from the recalled pregnancy to control for recall bias. The analysis was weighted for sampling probability. The population-attributable fraction was estimated by multiplying the adjusted odds ratio resulting from the multivariate logistic regression by the proportion of cases exposed to a risk factor, as explained by Rockhill et al. ${ }^{(23)}$. The population-attributable fraction was calculated to estimate the proportion of poor adherence to the IFA supplementation programme that would be prevented or reduced following elimination of the significant factors associated with the poor adherence found in the regression analysis. All statistical analysis was carried out using the statistical software package IBM SPSS Statistics for Windows, Version 20.0.

\section{Results}

Separate multivariate logistic regression analysis for each year showed that the factors significantly associated with adherence were similar across the years, except for perceived problems accessing health services (which was not 
among the significant factors in 2007) and type of residence (which was a significant factor only in 2012). Considering the high levels of similarity (both the proportion of adherence to the IFA supplementation programme and the associated factors), the present analysis used pooled data from the series of the three IDHS reports.

Table 1 presents the characteristics of the participants included in the analysis. In total, only less than $30 \%$ of the women consumed minimally ninety IFA tablets as recommended. The figure was quite similar across years, i.e. $28 \cdot 3 \%$ in 2002-03, 30.2\% in both 2007 and 2012. Unexpectedly, the proportion of women who did not consume any IFA tablets increased across the years (22.8, 23.1 and $26 \cdot 6 \%$ in 2002-03, 2007 and 2012, respectively).

Half of the women were $25-34$ years old and more than half were pregnant with their second child or greater. Maternal education was generally low, with more than $40 \%$ of the women not finishing primary education (had $<9$ years of schooling). About one-third of the women perceived having at least one problem accessing health services, particularly with getting money for treatment (perceived by $22.4 \%$ of the women). An inadequate frequency of ANC visits occurred mainly because the women, mostly those of low socio-economic status, did not have any ANC visits during the first trimester of pregnancy (20\%). Most women (>80\%) went to midwives for their ANC.

Television was the more common source of exposure to information for the women compared with the radio, magazines or newspapers. Yet, approximately $20 \%$ women had never watched television or watched it less than once weekly. Almost half of the women did not know problems that may occur during pregnancy as well as delivery. Approximately $8 \%$ of the women received no family support (i.e. approximately $30 \%$ of the women were not accompanied by their husband for any ANC visit and almost $20 \%$ of the women never had any discussion about delivery-related issues during the recalled pregnancy). Among the women who had discussions, the topics were primarily about the place for delivery and their birth attendant.

The bivariate logistic regression analysis demonstrated that significantly higher odds for having good adherence were observed among the women who were pregnant with their first child; those who were more educated, wealthier and more exposed to mass media; as well as among women who perceived having no problem accessing health services, had an adequate frequency of ANC visits, had better knowledge of pregnancy-related risks and received family support (Table 2).

Household wealth index, women's knowledge of pregnancy-related risks, adequacy of frequency of ANC visits and family support remained significant in the multivariate logistic regression. Further analysis from nearly 4000 husbands of the women in the study
Table 1 Characteristics of participants: women who had given birth within 2 years prior to the interview date; 2002-03, 2007 and 2012 Indonesia Demographic and Health Survey

\begin{tabular}{|c|c|c|}
\hline Characteristic & $n \dagger$ & $\%$ \\
\hline \multicolumn{3}{|l|}{ Dependent variable } \\
\hline \multicolumn{3}{|l|}{ IFA tablet consumption ( $n$ 16900) } \\
\hline 0 (did not consume any tablets) & 4097 & $24 \cdot 2$ \\
\hline $1-29$ tablets & 3701 & 21.9 \\
\hline $30-59$ tablets & 2588 & $15 \cdot 3$ \\
\hline $60-89$ tablets & 1507 & 8.9 \\
\hline$\geq 90$ tablets & 5006 & $29 \cdot 6$ \\
\hline \multicolumn{3}{|l|}{ Independent variables } \\
\hline \multicolumn{3}{|l|}{ Residence } \\
\hline Rural & 10330 & $54 \cdot 0$ \\
\hline Urban & 8803 & $46 \cdot 0$ \\
\hline \multicolumn{3}{|l|}{ Women's age } \\
\hline$<25$ years & 6023 & 31.5 \\
\hline $25-34$ years & 9500 & $49 \cdot 6$ \\
\hline$\geq 35$ years & 3611 & $18 \cdot 9$ \\
\hline \multicolumn{3}{|l|}{ Pregnancy order } \\
\hline Not the first child & 12250 & $64 \cdot 0$ \\
\hline The first child & 6883 & $36 \cdot 0$ \\
\hline \multicolumn{3}{|l|}{ Women's educational level ( $n$ 19124) } \\
\hline $0-5$ years of schooling & 2473 & $12 \cdot 9$ \\
\hline $6-8$ years of schooling & 5832 & 30.5 \\
\hline $9-11$ years of schooling & 4287 & $22 \cdot 4$ \\
\hline$\geq 12$ years of schooling & 6531 & $34 \cdot 2$ \\
\hline \multicolumn{3}{|l|}{$\begin{array}{l}\text { Perceived problems accessing health } \\
\text { services }(n 19085)\end{array}$} \\
\hline Have at least one problem & 6585 & 34.5 \\
\hline Have no problem at all & 12500 & 65.5 \\
\hline \multicolumn{3}{|l|}{$\begin{array}{l}\text { Women's exposure to three types of } \\
\text { mass media ( } n 19084)\end{array}$} \\
\hline Less exposed & 3216 & $16 \cdot 9$ \\
\hline Frequently exposed to one type of media & 10324 & $54 \cdot 1$ \\
\hline $\begin{array}{l}\text { Frequently exposed to more than one } \\
\text { type of media }\end{array}$ & 5544 & $29 \cdot 0$ \\
\hline \multicolumn{3}{|l|}{ Frequency of ANC visits ( $n$ 19020) } \\
\hline Inadequate & 6337 & 33.7 \\
\hline Adequate & 12683 & $66 \cdot 3$ \\
\hline \multicolumn{3}{|l|}{$\begin{array}{l}\text { Women's knowledge of pregnancy-related } \\
\text { risks }(n 19121)\end{array}$} \\
\hline Has no knowledge & 6717 & $35 \cdot 1$ \\
\hline Has some knowledge & 7340 & 38.4 \\
\hline Has good knowledge & 5064 & $26 \cdot 5$ \\
\hline \multicolumn{3}{|l|}{ Family support during pregnancy ( $n$ 18273) } \\
\hline Received no support & 1456 & 8.0 \\
\hline Received some support & 10048 & $55 \cdot 0$ \\
\hline Received full support & 6769 & $37 \cdot 0$ \\
\hline
\end{tabular}

IFA, iron-folic acid; ANC, antenatal care.

†Weighted total was 19133 unless stated otherwise in parentheses.

demonstrated that the women whose husbands talked to health providers about their wife's health during pregnancy had significantly higher adherence than women whose husbands did not report this practice (39.2 v. $27 \cdot 0 \%$, respectively, $P<0 \cdot 05$ ). Other factors, i.e. more exposure to mass media and having no perceived problem accessing health services, were also significantly associated with a higher likelihood of adherence in the multivariate logistic regression. However, the effect size was small compared with that of the other factors.

Considering that IFA tablets are distributed (or prescribed) through health services when women have ANC visits, we performed further analysis to observe the 'flow' from 'supply to consumption' (i.e. frequency of ANC visits, 
Table 2 Factors associated with adherence to maternal iron-folic acid supplementation (unadjusted and adjusted odds ratiost) among women who had given birth within 2 years prior to the interview date; 2002-03, 2007 and 2012 Indonesia Demographic and Health Survey

\begin{tabular}{|c|c|c|c|c|c|c|c|c|}
\hline \multirow[b]{2}{*}{ Characteristic } & \multirow[b]{2}{*}{$n$} & \multirow{2}{*}{$\begin{array}{c}\text { Good } \\
\text { adherence (\%) }\end{array}$} & \multicolumn{3}{|c|}{ Unadjusted } & \multicolumn{3}{|c|}{ Adjusted $\neq$} \\
\hline & & & cOR & $95 \% \mathrm{Cl}$ & $P$ & $\mathrm{aOR}$ & $95 \% \mathrm{Cl}$ & $P$ \\
\hline \multicolumn{9}{|l|}{ Type of residence } \\
\hline Rural & 9273 & $24 \cdot 9$ & Ref. & & & Ref. & & \\
\hline Urban & 7627 & $35 \cdot 3$ & 1.6 & $1.5,1 \cdot 8$ & 0.00 & 1.0 & $0.9,1.1$ & 0.62 \\
\hline \multicolumn{9}{|l|}{ Wealth index } \\
\hline Poorest & 3263 & $17 \cdot 0$ & Ref. & & & Ref. & & \\
\hline Poorer & 3183 & $25 \cdot 5$ & 1.7 & $1.5,1.9$ & 0.00 & 1.3 & $1.1,1.4$ & 0.00 \\
\hline Medium & 3285 & $29 \cdot 7$ & $2 \cdot 1$ & $1 \cdot 8,2 \cdot 3$ & 0.00 & 1.4 & $1 \cdot 2,1 \cdot 6$ & 0.00 \\
\hline Richer & 3325 & 28.6 & $2 \cdot 1$ & $1.9,2.4$ & 0.00 & 1.3 & $1 \cdot 1,1.4$ & 0.00 \\
\hline Richest & 2901 & 37.7 & 3.5 & $3 \cdot 1,3.9$ & 0.00 & 1.6 & $1.4,1.9$ & 0.00 \\
\hline \multicolumn{9}{|l|}{ Women's educational level } \\
\hline $0-5$ years of schooling & 1929 & $18 \cdot 7$ & Ref. & & & Ref. & & \\
\hline $6-8$ years of schooling & 4916 & $27 \cdot 2$ & 1.6 & $1.4,1.9$ & 0.00 & $1 \cdot 2$ & $0.9,1.4$ & 0.06 \\
\hline $9-11$ years of schooling & 3726 & $30 . \overline{6}$ & 1.9 & $1 \cdot 7,2 \cdot 2$ & 0.00 & $1 \cdot 1$ & $0.9,1.3$ & 0.40 \\
\hline$\geq 12$ years of schooling & 5387 & $39 \cdot 1$ & $2 \cdot 8$ & $2 \cdot 5,3 \cdot 2$ & 0.00 & $1 \cdot 1$ & $0.9,1.3$ & 0.25 \\
\hline \multicolumn{9}{|l|}{ Women's exposure to three types of mass media } \\
\hline Less exposed & 2554 & $21 \cdot 1$ & ref & Ref. & & Ref. & & \\
\hline Frequently exposed to one type of media & 8711 & 30.9 & 1.7 & $1.5,1.9$ & 0.00 & $1 \cdot 10$ & $1 \cdot 0,1 \cdot 2$ & 0.15 \\
\hline Frequently exposed to more than one type of media & 4694 & $36 \cdot 5$ & $2 \cdot 2$ & $1.9,2.4$ & 0.00 & $1 \cdot 16$ & $1.0,1.3$ & 0.01 \\
\hline \multicolumn{9}{|l|}{ Perceived problems accessing health services } \\
\hline Have at least one problem & 5345 & 24.9 & Ref. & & & Ref. & & \\
\hline Have no problems & 10614 & $34 \cdot 0$ & 1.6 & $1.5,1 \cdot 7$ & 0.00 & 1.3 & $1.2,1.4$ & 0.00 \\
\hline \multicolumn{9}{|l|}{ Frequency of ANC visits } \\
\hline Inadequate & 5159 & $17 \cdot 1$ & Ref. & & & Ref. & & \\
\hline Adequate & 10799 & $37 \cdot 6$ & $2 \cdot 9$ & $2 \cdot 7,3 \cdot 2$ & 0.00 & $2 \cdot 2$ & $2 \cdot 0,2 \cdot 4$ & 0.00 \\
\hline \multicolumn{9}{|l|}{ Women's knowledge of pregnancy-related risks } \\
\hline Has no knowledge & 5506 & 21.4 & Ref. & & & Ref. & & \\
\hline Has some knowledge & 6189 & $32 \cdot 9$ & 1.8 & $1 \cdot 7,2 \cdot 0$ & 0.00 & 1.5 & $1.4,1.7$ & 0.00 \\
\hline Has good knowledge & 4262 & 40.5 & 2.5 & $2 \cdot 3,2 \cdot 8$ & 0.00 & 1.8 & $1 \cdot 6,2 \cdot 0$ & 0.00 \\
\hline \multicolumn{9}{|l|}{ Family support during pregnancy } \\
\hline Received no support & 1323 & $16 \cdot 1$ & Ref. & & & Ref. & & \\
\hline Received some support & 8881 & $27 \cdot 1$ & $2 \cdot 0$ & $1 \cdot 7,2 \cdot 3$ & 0.00 & 1.3 & $1 \cdot 1,1 \cdot 6$ & 0.00 \\
\hline Received full support & 5754 & $40 \cdot 4$ & 3.7 & $3 \cdot 2,4 \cdot 3$ & 0.00 & 1.9 & $1 \cdot 6,2 \cdot 3$ & 0.00 \\
\hline
\end{tabular}

cOR, crude odds ratio; aOR, adjusted odds ratio; ANC, antenatal care; ref., reference category.

†Only included participants with no missing values for independent and dependent variables ( $n$ 15958).

$\ddagger$ Adjusted by year of survey, pregnancy order, child's age and women's age.

provision of IFA tablets, women's knowledge and women's adherence). The results are shown in Tables 3 and 4. Unexpectedly, $15.5 \%$ of the women who had adequate ANC visits reported never receiving or buying any IFA tablets during the recalled pregnancy. Because the distribution of IFA tablets is expected to be performed along with health/nutrition counselling, we analysed the association between the women's knowledge and the adequacy of their ANC visit frequency. A significantly higher proportion of women with good knowledge was observed among those with an adequate frequency of ANC visits $(30.6 v$. $18.5 \%$, respectively, $P<0.001)$. Nevertheless, nearly one-third of the women with an adequate frequency of ANC visits did not have enough knowledge.

Further analysis showed that there was a significant interaction between the women's educational level and family support $(P=0 \cdot 01)$. The results are outlined in Fig. 2 (see online supplementary material, Supplemental Table 1). The odds of adherence were not significantly different among women who did not receive support from their family, regardless of their educational level. Meanwhile, family support significantly increased the likelihood of adherence among poorly educated women (had $<9$ years of schooling). Among the most poorly educated women ( $<6$ years of schooling), some support and full support from the family were able to increase the likelihood of adherence by 1.65 (95\% CI $1.18,2.32)$ and 1.98 (95\% CI $1.50,2.33)$ times, respectively. Among the women with 6-8 years of schooling, full support from the family increased the likelihood of adherence by $2 \cdot 70$ (95\% CI 1.24, 8.74) times. Support from the family also increased the odds of adherence among women with $\geq 9$ years of schooling, but the difference was not statistically significant.

Calculation of the population-attributable fraction showed that while the distributions of other associated factors in the population remain unchanged, the proportion of women with poor adherence to the IFA supplementation programme would be estimated to be reduced by $24.4 \%$ if all of the women had adequate frequencies of ANC visits, by $23 \cdot 1 \%$ if all women received full support from their families, by $16.4 \%$ if all women had at least some knowledge of pregnancy-related risks, by $9 \cdot 1 \%$ if all women had no perceived problems accessing 
Table 3 Missed opportunities for health-care providers to provide a sufficient supply of iron-folic acid (IFA) tablets during antenatal care (ANC) visits by women who had given birth within 2 years prior to the interview date; 2002-03, 2007 and 2012 Indonesia Demographic and Health Survey

\begin{tabular}{llcc}
\hline & & \multicolumn{2}{c}{ Adhered (took $\geq 90$ IFA tablets) } \\
\cline { 3 - 4 } Frequency of ANC visits & $\begin{array}{l}\text { Received/bought } \\
\text { IFA tablets }\end{array}$ & $n$ & $\%$ \\
\hline Inadequate $(n 5159,32.3 \%)$ & No $(n 1628,31.6 \%)$ & - & - \\
Adequate $(n 10799,67.7 \%)$ & Yes $(n 3531,68.4 \%)$ & 883 & 25.0 \\
& No $(n 1677,15.5 \%)$ & - & - \\
\hline
\end{tabular}

Table 4 Missed opportunities for health-care providers to provide sufficient knowledge during antenatal care (ANC) visits by women who had given birth within 2 years prior to the interview date; 2002-03, 2007 and 2012 Indonesia Demographic and Health Survey

\begin{tabular}{|c|c|c|c|c|c|}
\hline \multirow[b]{2}{*}{ Frequency of ANC visits } & \multirow[b]{2}{*}{$P+$} & \multirow{2}{*}{$\begin{array}{l}\text { Knowledge of } \\
\text { pregnancy-related risks }\end{array}$} & \multicolumn{2}{|c|}{ Adhered (took $\geq 90$ IFA tablets) } & \multirow[b]{2}{*}{$P \ddagger$} \\
\hline & & & $n$ & $\%$ & \\
\hline \multirow[t]{3}{*}{ Inadequate ( $n 5159,32.3 \%)$} & $<0.001$ & $\begin{array}{l}\text { No knowledge } \\
\quad(n 2323,45.0 \%)\end{array}$ & 300 & $12 \cdot 9$ & $<0.001$ \\
\hline & & $\begin{array}{l}\text { Some knowledge } \\
\quad(n 1880,36.4 \%)\end{array}$ & 369 & $19 \cdot 6$ & \\
\hline & & $\begin{array}{l}\text { Good knowledge } \\
\quad(n 956,18.5 \%)\end{array}$ & 214 & $22 \cdot 4$ & \\
\hline \multirow[t]{3}{*}{ Adequate ( $n 10799,67.7 \%)$} & & $\begin{array}{l}\text { No knowledge } \\
\quad(n 3184,29.5 \%)\end{array}$ & 878 & $27 \cdot 6$ & $<0.001$ \\
\hline & & $\begin{array}{l}\text { Some knowledge } \\
\quad(n 4308,39.9 \%)\end{array}$ & 1670 & $38 \cdot 8$ & \\
\hline & & $\begin{array}{l}\text { Good knowledge } \\
\quad(n 3307,30.6 \%)\end{array}$ & 1514 & $45 \cdot 8$ & \\
\hline
\end{tabular}

IFA, iron-folic acid.

†Association between adequacy of ANC visit frequency and knowledge of pregnancy-related risks.

$\ddagger$ Association between knowledge of pregnancy-related risks and IFA supplementation adherence, by adequacy of ANC visit frequency.

health services and by $8.4 \%$ if the household's wealth was improved to a medium-high level. Considering that access to health services and household wealth are less modifiable, an integrated approach focusing on women with inappropriate frequencies of ANC visits, women with no knowledge of pregnancy-related risks and women who do not receive full support from their families is estimated to reduce the proportion of poor adherence to IFA supplementation by approximately $63.9 \%$.

\section{Discussion}

The pattern of women's adherence to IFA tablet consumption during pregnancy was similar in 2002-03, 2007 and 2012, indicating that almost no improvement was achieved after 10 years. The present study confirms previous findings, which suggested that an adequate frequency of ANC visits, better knowledge of maternal risks and danger signs, and family support significantly increase the likelihood of women to adhere to the IFA supplementation programme recommendation ${ }^{(4,8,11,22,24)}$.

Studies show that the frequency of ANC visits is associated with access to health services ${ }^{(25,26)}$, which was also observed in the present analysis. As previously mentioned, getting money for treatment was perceived by a majority of women as a problem in accessing health facilities. Nevertheless, the DHS questionnaire refers to health-care facilities in general, and thus the women may not necessarily have trouble accessing health facilities that have ANC services. In Indonesia, women who seek ANC service at government health facilities receive IFA tablets for free. In addition, IFA tablets are also distributed free of charge through monthly ANC services performed by the primary health-care midwife at local health posts (Posyandu). Posyandu is a community-based organization established at the hamlet level (the lower level of a sub-district) and thus is expected to be more accessible by the pregnant women in terms of distance and also cost of transportation.

On the other hand, the current analysis showed that one-third of women with no problems accessing health services had an inadequate frequency of ANC visits, primarily during the first trimester. This may be due to the women not being aware that they are pregnant, as another study suggested that women tend to report their pregnancy for the first time to their health-care provider at approximately 16 weeks of gestational age ${ }^{(27)}$. In addition, women's perception that ANC is necessary only if they have problems in their pregnancy may also prevent the women from seeking services ${ }^{(26)}$. In term of IFA 


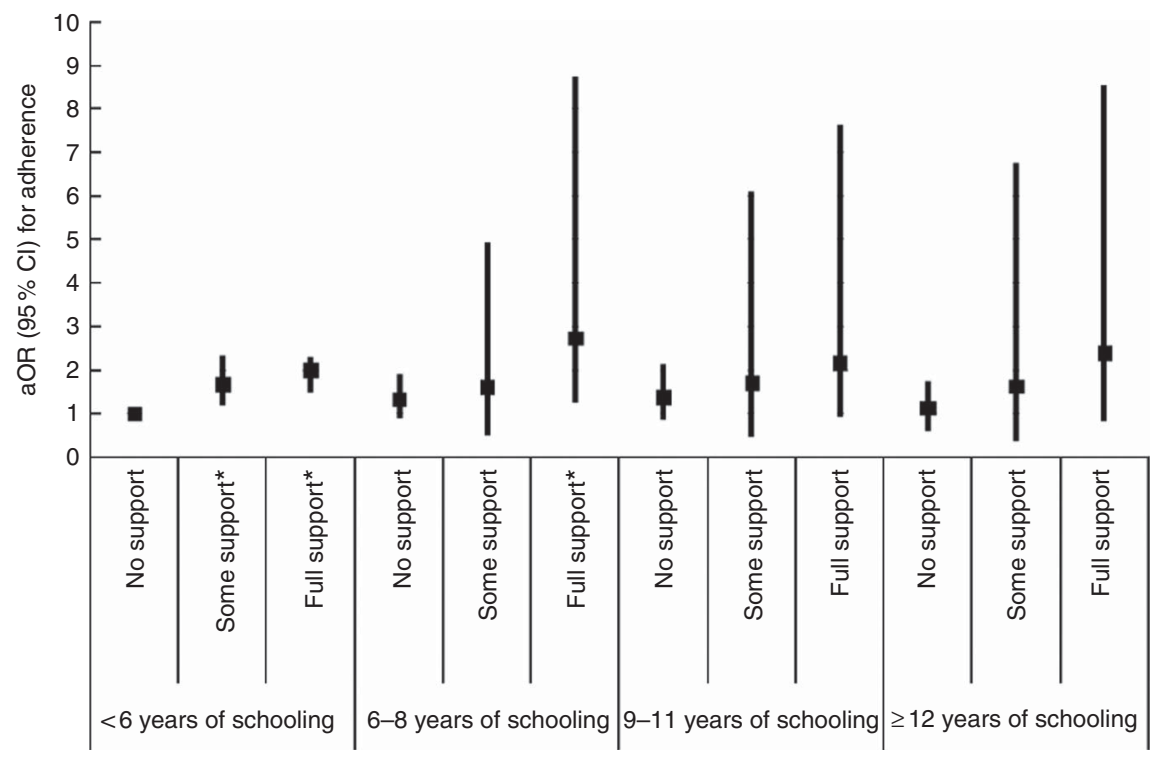

Fig. 2 Adjusted odds ratio (aOR), with $95 \%$ confidence interval represented by vertical bars, for adherence to maternal iron-folic acid supplementation by women's educational level and family support among women $(n 19133)$ who had given birth within 2 years prior to the interview date; 2002-03, 2007 and 2012 Indonesia Demographic and Health Survey. Analysis controlled for sociodemographic characteristics, frequency of antenatal care visits, women's exposure towards information and knowledge of pregnancy-related risks $\left({ }^{*} P<0.05\right)$

adherence, early ANC provides more time for the women to feel the health benefits of IFA tablets and thus motivates them to continue taking the tablets ${ }^{(28)}$, as found in studies in India ${ }^{(11)}$, the Philippines ${ }^{(7)}$, Senegal ${ }^{(8)}$, Vietnam ${ }^{(5)}$ and $\mathrm{Nepal}^{(20)}$.

An adequate number of ANC visits increases the opportunity for women to receive a sufficient number of IFA tablets as well as to have regular contact with health-care providers. The regular contact may then increase the chance that the women will receive encouragement from their health-care providers to continuously take the tablets ${ }^{(29)}$. Nevertheless, we observed two types of missed opportunities for healthcare providers to use ANC visits to promote IFA tablet consumption. First, $15.5 \%$ of the women with adequate ANC visits reported not receiving/buying IFA tablets during pregnancy. Inadequate supply is one of the factors suggested by previous studies that is associated with a low consumption of IFA tablets ${ }^{(3,24,28,30,31)}$. A qualitative study in Indonesia, for example, revealed that not all women reported receiving minimally ninety tablets during pregnancy ${ }^{(26)}$. However, in the IDHS data sets used in the present analysis, there was no information on the number of IFA tablets that were received/bought by the women during the recalled pregnancy. Second, almost $30 \%$ of the women with an adequate frequency of ANC visits did not have knowledge of pregnancy-related risks, suggesting that education and counselling for the women was not optimally performed during the ANC visits.

Ideally, ANC visits are used as the best opportunity for health staff to deliver health and nutritional preventive services, including providing the women with education and counselling ${ }^{(32)}$. On the other hand, studies also highlight the limited capacity of health personnel to perform counselling as one of the factors that made implementation of the IFA supplementation programme not occur as expected ${ }^{(30)}$. One study in Uganda, for example, reported that mothers were mostly considered passive recipients during the pregnancy check-up visits and the delivery of information was more in the form of instructions. Therefore, despite having good ANC attendance, the mothers were not adequately prepared with regard to pregnancy care as well as newborn care ${ }^{(33)}$. A qualitative study in eight developing countries also indicated that most women attending ANC visits were aware about the recommendation to consume Fe tablets or other prenatal vitamins. However, the women were not told why the tablets were prescribed ${ }^{(24,34)}$.

Studies, as well as the present analysis, demonstrate that the provision of knowledge plays a major role in women's good adherence to IFA supplementation. The knowledge can be focused on the specific function of the IFA tablets, as reported in a study in Senegal ${ }^{(8)}$, or on anaemia, as reported in a study in Indonesia ${ }^{(22)}$. In the present study, the women's knowledge focused on knowledge of the risks or danger signs during pregnancy/ delivery/postpartum. The knowledge is considered to represent the women's awareness of the risks they may have, which thus leads them to minimize the risk, for example by taking the IFA tablets. One review highlights the need to address specific messages on the increased risk of both maternal and infant death/illness at birth due 
to anaemia during pregnancy, to improve women's adherence in taking IFA tablets ${ }^{(21)}$. The message is important because women may have misperceptions of the signs of anaemia and accept them as normal during pregnancy $^{(21,35)}$.

Family support was also among the significant factors in adherence. In the current analysis, the proportion of women who reported 'not wanting to go alone' as a problem accessing health services increased almost three times in 2012 (20.8\%) compared with 2002-03 (8.8\%). This suggests the increased expectation of the women to be accompanied when having health services, which may also include the ANC visits. Notably, the proportion of women with an adequate frequency of ANC visits was significantly higher among women accompanied by their husbands compared with those who were not (75.5 $v$. $51.6 \%$, respectively). This influence on the adequacy of ANC visit frequency signifies the increased role of the family in the women's adherence. Another study in Indonesia and one study in South Africa showed that most women preferred their husbands to be involved in maternal care, including accompanying the women for pregnancy check-ups ${ }^{(36,37)}$.

Another important role of the family in terms of adherence to IFA tablet consumption is to remind the women to take the tablets regularly. This role is essential because previous studies show that among the main reasons for women not taking Fe tablets as recommended is forgetfulness ${ }^{(7,8,20,38)}$. As reported by a study in India, encouragement from family meant that the women were able to continue taking the tablets despite their forgetfulness ${ }^{(11)}$. Women in Vietnam also reported asking their husbands to remind them to not forget to take the tablets $^{(5)}$. One review describes that taking pills daily for a long time period is perceived by the women to be a hard thing to do ${ }^{(21)}$ and is also perceived as one of the constraints faced by women with low compliance ${ }^{(8)}$. Encouragement from families may thus motivate the women, particularly when they start feeling bored, to continue taking the tablets. Moreover, as suggested by an intervention study in Indonesia, when pregnant women are supported in taking supplements, combined with good supplement distribution, adherence is not a problem $^{(39)}$.

Further analysis showed that family support was significantly related to the women's educational level. Family support was able to significantly increase the likelihood of less-educated women adhering to IFA supplementation. One study noted that translating intention into action may be less easy for less-educated people, as people need to be ready and feel able to make behavioural changes ${ }^{(40)}$. Therefore, less-educated women may need more help from their environment, and their families can be a source of information about or reinforcement of the behaviour. In the current study, family support was primarily in the form of the partner accompanying the women to pregnancy check-ups as well as discussing delivery plan-related issues. An intervention study involving husbands in promoting women's reproductive health suggested that increased communication and interaction between couples during or after the education session might lead to a greater understanding of new information ${ }^{(41)}$.

In contrast, non-significantly higher odds of adherence were observed among more-educated women, despite the full support received from their families. This suggests that the more-educated women by themselves might have sufficient awareness and understanding of pregnancy care, including the importance of taking IFA tablets during pregnancy. Studies indicate that more-educated women are more interested in seeking information ${ }^{(40,42)}$. In addition, as stated by Rosenzweig (1995) in Cutler and Lieras-Murney $^{(40)}$, education improves the individual's ability to understand information. A combination of seeking more information and having a higher ability to understand it might contribute to the less significant role of family support in adherence to IFA supplementation among the more-educated women.

Women from households of higher wealth quintile, particularly the wealthiest, have better adherence compared with the less wealthy women. In the current study, almost half of the wealthiest women had their pregnancy check-ups with a gynaecologist. In comparison, the proportion was less than $10 \%$ among women from medium-wealth households. It is assumed that the wealthiest women might receive better counselling on pregnancy care, including the rationale for taking IFA tablets during pregnancy. Moreover, the wealthiest women were also the most-educated women who, in general, have higher health consciousness and are more likely to comply with a healthy lifestyle. In addition, our qualitative study (LAA Wiradnyani, unpublished results) shows that wealthier women can afford to buy types of IFA tablets which fit the women's preference, i.e. have pleasant taste and smell, despite their higher price. The unpleasant taste and smell of IFA tablets are reported in several previous studies as among the reasons for low adherence $^{(5,7)}$.

\section{Strengths and limitations of the study}

The use of three data sets of nationally representative surveys using standardized methods and covering a period of 10 years is one of the strengths of the current study. The results of the multivariate analysis were adjusted by the year of the survey, and thus the study is able to examine the factors associated with adherence to IFA supplementation for the period of the last 10 years. The second strength is the identification of the importance of family support and women's knowledge as factors associated with adherence. Both factors, especially family support, are less explored in previous studies. 
As a limitation of the present study, the explanatory factors described herein were based on available variables in the IDHS data set and thus did not include other potential factors found to be associated with adherence in taking IFA tablets in previous studies, for example counselling and motivation received from the health-care provider $^{(6,30)}$ and perceived side-effects ${ }^{(5,7)}$. However, many studies suggest that the impact of side-effects has been overemphasized because it was found to have a minor influence on adherence ${ }^{(6,10,20)}$.

\section{Conclusion}

The present analysis highlights the importance of having an adequate frequency of ANC visits, good knowledge of pregnancy-related risks and support from family in increasing women's adherence to taking IFA tablets during pregnancy. The missed opportunities identified in the current study must be minimized by making use of ANC visits as a medium to provide women with sufficient numbers of IFA tablets, along with providing specific information on pregnancy care, including pregnancyrelated risks. Encouraging women to have an adequate frequency of ANC visits (especially during the first trimester) is a must. As the inadequate frequency of ANC visits occurred mostly among women of low socio-economic status, it is important to strengthen the ANC services at Posyandu, which is more accessible for them and has a fixed schedule, by increasing the role of community health workers and midwives for the early detection of pregnancy. Family members, and particularly the husband, must be included as targets of pregnancy care programmes, especially among less-educated women. Family members should be encouraged to be actively involved as the women's partners for ANC visits, as well as for the discussion of pregnancy and delivery issues and providing 'reminders' for tablet consumption.

\section{Acknowledgements}

Acknowledgements: The authors thank Atmarita, $\mathrm{PhD}$, Professor Hardinsyah, PhD and Airin Roshita, PhD for their advice to sharpen the analysis and discussion. Financial support: L.A.A.W. received a scholarship for doctorate study, attending the course and workshop at the Harvard School of Public Health entitled 'Analysis of Health and Nutrition Data from Low-Income Countries', and support for manuscript preparation and analysis from the Higher Education Network Ring Initiative (HENRI) Program, a partnership supported by a grant from the US Agency for International Development-Indonesia (Cooperative Agreement AID-497-A-11-00002) to the Harvard School of Public Health in partnership with, and with in-kind contributions from, the SEAMEO Regional Centre for
Food and Nutrition, Universitas Indonesia, University of Mataram, Andalas University, the Summit Institute of Development and Helen Keller International, with additional contributions from the Rajawali Foundation and Harvard Kennedy School Indonesia Program. Conflict of interest: None. Authorship: The study was designed by L.A.A.W., H.K., E.L.A., D.O. and A.H.S. Data analysis was done by L.A.A.W., supervised by H.K. and A.H.S. First draft of the article was written by L.A.A.W. and then all co-authors contributed to finalize the article. Ethics of buman subject participation: In the IDHS data sets used for this analysis, the confidentiality and anonymity of the names, addresses and locations of the study participants were kept by the data source. The researchers had no attention to seek the subjects' identity. This secondary data analysis obtained ethical clearance from the Ethical Committee of the Faculty of Medicine, Universitas Indonesia (ethics number 07/H2.F1/ETIK/2014) on 6 January 2014.

\section{Supplementary material}

To view supplementary material for this article, please visit http://dx.doi.org/10.1017/S1368980016001002

\section{References}

1. Lynch S (2007) Iron metabolism. In Nutritional Anemia, pp. 59-76 [K Kraemer and M Zimmermann, editors]. Basel: Sight and Life Press.

2. World Health Organization (2001) Iron Deficiency Anaemia: Assessment, Prevention and Control. A Guide for Programme Managers. Geneva: WHO.

3. Yip R (2002) Iron supplementation: country level experiences and lessons learned. J Nutr 132, 4 Suppl., 859S-861S.

4. Deitchler M, Mathys E, Mason J et al. (2004) Lessons from successful micronutrient programs. Part II: program implementation. Food Nutr Bull 25, 30-52.

5. Aikawa R, Jimba M, Nguen KC et al. (2006) Why do adult women in Vietnam take iron tablets? BMC Public Health 6, 144 .

6. Risonar MGD, Rayco-Solon P, Tengco LW et al. (2009) Effectiveness of a redesigned iron supplementation delivery system for pregnant women in Negros Occidental, Philippines. Public Health Nutr 12, 932-940.

7. Lutsey PL, Dawe D, Villate E et al. (2008) Iron supplementation compliance among pregnant women in Bicol, Philippines. Public Health Nutr 11, 76-82.

8. Seck BC \& Jackson RT (2008) Determinants of compliance with iron supplementation among pregnant women in Senegal. Public Health Nutr 11, 596-605.

9. Ogundipe O, Hoyo C, Østbye T et al. (2012) Factors associated with prenatal folic acid and iron supplementation among 21,889 pregnant women in Northern Tanzania: a crosssectional hospital-based study. BMC Public Health 12, 481.

10. Hyder SMZ, Persson LA, Chowdhury AMR et al. (2002) Do side-effects reduce compliance to iron supplementation? A study of daily- and weekly-dose regimens in pregnancy. J Health Popul Nutr 20, 175-179.

11. Ghanekar J, Kanani S \& Patel S (2002) Toward better compliance with iron-folic acid supplements: understanding the behavior of poor urban pregnant women 
through ethnographic decision models in Vadodara, India. Food Nutr Bull 23, 65-72.

12. Ministry of Health (1999) Pedoman pemberian tablet besifolat dan sirup besi bagi petugas (Iron-Folic Acid Tablets and Iron Syrup Distribution: A Guideline for Health Staff), 3rd ed. Jakarta: Indonesian Ministry of Health.

13. Mason J, Deitchler M, Mathys E et al. (2004) Lessons from successful micronutrient programs. Part III: program impact. Food Nutr Bull 25, 53-78.

14. Statistics Indonesia \& ORC Macro (2003) Indonesia Demographic and Health Survey 2002-2003. Calverton, MD: BPS and ORC Macro.

15. McLean E, Egli I, Cogswell M et al. (2007) Worldwide prevalence of anemia in preschool aged children, pregnant women and non-pregnant women of reproductive age. In Nutritional Anemia, pp. 1-12 [K Kraemer and M Zimmermann, editors]. Basel: Sight and Life Press.

16. Statistics Indonesia \& Macro International (2007) Indonesia Demographic and Health Survey 2007. Calverton, MD: BPS and Macro International.

17. Statistics Indonesia, National Population and Family Planning Board, Kementerian Kesehatan et al. (2012) Indonesia Demographic and Health Survey 2012. Jakarta: BPS, BKKBN, Kemenkes and ICF International.

18. Hector D, King L, Webb K et al. (2005) Factors affecting breastfeeding practices. Applying a conceptual framework. NSW Public Health Bull 16, 52-55.

19. Dibley MJ, Titaley CR, d'Este C et al. (2012) Iron and folic acid supplements in pregnancy improve child survival in Indonesia. Am J Clin Nutr 95, 220-230.

20. Kulkarni B, Christian P, LeClerq SC et al. (2010) Determinants of compliance to antenatal micronutrient supplementation and women's perceptions of supplement use in rural Nepal. Public Health Nutr 13, 82-90.

21. Nagata JM, Gatti LR \& Barg FK (2012) Social determinants of iron supplementation among women of reproductive age: a systematic review of qualitative data. Matern Child Nutr 8, $1-18$

22. Souganidis ES, Sun K, de Pee S et al. (2012) Relationship of maternal knowledge of anemia with maternal and child anemia and health-related behaviors targeted at anemia among families in Indonesia. Matern Child Health $J \mathbf{1 6}$, 1913-1925.

23. Rockhill B, Newman B \& Weinberg C (1998) Use and misuse of population attributable fractions. Am J Public Health 88, 15-19.

24. Galloway R, Dusch E, Elder L et al. (2002) Women's perceptions of iron deficiency and anemia prevention and control in eight developing countries. Soc Sci Med 55, 529-544.

25. Simkhada B, Teijlingen ER, van, Porter M et al. (2008) Factors affecting the utilization of antenatal care in developing countries: systematic review of the literature. J Adv Nurs 61, 244-260.

26. Titaley CR, Hunter CL, Heywood P et al. (2010) Why don't some women attend antenatal and postnatal care services? A qualitative study of community members' perspectives in
Garut, Sukabumi and Ciamis districts of West Java Province, Indonesia. BMC Pregnancy Childbirth 10, 61.

27. Berger J, Wieringa FT, Lacroux A et al. (2011) Strategies to prevent iron deficiency and improve reproductive health. Nutr Rev 69, Suppl. 1, S78-S86.

28. Galloway R \& McGuire J (1994) Determinants of compliance with iron supplementation: supplies, side effects, or psychology? Soc Sci Med 39, 381-390.

29. Mora JO (2002) Iron supplementation: overcoming technical and practical barriers. J Nutr 132, 4 Suppl., 853S-855S.

30. Mason JB, Saldanha LS, Ramakrishnan U et al. (2012) Opportunities for improving maternal nutrition and birth outcomes: synthesis of country experiences. Food Nutr Bull 33, 2 Suppl., S104-S137.

31. Sanghvi TG, Harvey PWJ \& Wainwright E (2010) Maternal iron-folic acid supplementation programs: evidence of impact and implementation. Food Nutr Bull 31, 2 Suppl., S100-S107.

32. Mora JO \& Nestel PS (2000) Improving prenatal nutrition in developing countries: strategies, prospects, and challenges. Am J Clin Nutr 71, 1353S-1363S.

33. Ayiasi MR, Van Royen K, Verstraeten R et al. (2013) Exploring the focus of prenatal information offered to pregnant mothers regarding newborn care in rural Uganda. BMC Pregnancy Childbirth 13, 176.

34. Popa AD, Niţă O, Graur Arhire LI et al. (2013) Nutritional knowledge as a determinant of vitamin and mineral supplementation during pregnancy. BMC Public Health 13, 1105.

35. Chatterjee N \& Fernandes G (2014) 'This is normal during pregnancy': a qualitative study of anaemia-related perceptions and practices among pregnant women in Mumbai, India. Midwifery 30, e56-e63.

36. Februhartanty J (2008) Strategic Roles of Fathers in Optimizing Breastfeeding Practices: A Study in an Urban Setting of Jakarta. Jakarta: Faculty of Medicine University of Indonesia.

37. Mullick S, Kunene B \& Wanjiru M (2005) Involving men in maternity care: health service delivery issues. http://www. popcouncil.org/pdfs/frontiers/journals/Agenda_Mullick05. pdf (accessed October 2013).

38. Schultink W, van der Ree M, Matulessi P et al. (1993) Low compliance with an iron-supplementation program: a study among pregnant women in Jakarta, Indonesia. Am J Clin Nutr 57, 135-139.

39. Sunawang, Utomo B, Hidayat A et al. (2009) Preventing low birthweight through maternal multiple micronutrient supplementation: a cluster-randomized, controlled trial in Indramayu, West Java. Food Nutr Bull 30, 4 Suppl., S488-S495.

40. Cutler D \& Lieras-Murney A (2010) Understanding differences in health behaviors by education.J Health Econ 29, 1-28.

41. Mullany B, Becker S \& Hindin M (2007) The impact of including husbands in antenatal health education services on maternal health practices in urban Nepal: results from a randomized controlled trial. Health Educ Res 22, 166-176.

42. Hardinsyah (2007) Review on determinant factors of dietary diversity. Jurnal Gizi dan Pangan 2, 55-74. 